\title{
Long-range correlations of extrapolar total ozone are determined by the global atmospheric circulation
}

\author{
P. Kiss ${ }^{1}$, R. Müller ${ }^{2}$, and I. M. Jánosi ${ }^{1}$ \\ ${ }^{1}$ Department of Physics of Complex Systems, Eötvös University, Budapest, Hungary \\ ${ }^{2}$ ICG-1, Research Centre Jülich, Germany
}

Received: 24 April 2007 - Revised: 27 June 2007 - Accepted: 25 July 2007 - Published: 27 July 2007

\begin{abstract}
TOMS (Version 8) ozone records are analysed between latitudes $60^{\circ} \mathrm{S}$ and $60^{\circ} \mathrm{N}$, in order to extract autocorrelation properties with high spatial resolution. After the removal of semi-annual, annual, and quasi-biennial background oscillations, the residuals are evaluated by detrended fluctuation analysis. Long-range correlations are detected everywhere. Surprisingly, the latitude dependence of zonally averaged correlation exponents exhibits the same behaviour as the exponents for daily surface temperature records. This suggests that the correlation properties of total ozone column are dominated by the global atmospheric circulation patterns, and the effect of chemical processes seems to be subsidiary.
\end{abstract}

\section{Introduction}

There is a widespread interest in understanding the properties and dynamics of atmospheric ozone. Special attention is paid to the observed slow decline of the total amount of stratospheric ozone in the past decades, and the strong seasonal depletion over the polar regions known as ozone hole (e.g., Weatherhead and Andersen, 2006; WMO, 2007). In recent years, the question how a recovery of stratospheric ozone can be detected and attributed to the observed decline of the halogen loading has attracted considerable interest (WMO, 2007). The chemistry affecting stratospheric ozone is today largely understood and, likewise, the general mechanisms are known that determine the impact of dynamics on total column ozone (TO). Nonetheless, a reproduction of the interplay between chemistry and dynamics and the resulting ozone levels in models still constitutes a considerable challenge (Eyring et al., 2006) and extracting the chemical contribution to observed ozone trends is difficult (WMO, 2007). Deducing correlation properties from measured data

Correspondence to: I. M. Jánosi

(janosi@lecso.elte.hu) is a starting step to characterise the dynamics, and has also relevant implications in trend analysis (Vyushin et al., 2007).

The Total Ozone Mapping Spectrometers (TOMS) have been a successful series of instruments designed for measuring TO, and providing other products such as the aerosol index, reflectivity, ultraviolet radiation, and volcanic $\mathrm{SO}_{2}$ (http://toms.gsfc.nasa.gov/). Here we present a detailed analysis for two TO data sets collected on the satellites Nimbus-7 (N7) in the period 1 November 1978-6 May 1993, and EarthProbe (EP) between 25 July 1996 and 30 Dec. 2005. We use the method of detrended fluctuation analysis (DFA) (Peng et al., 1994, 1995), which is able to eliminate slow trends from long nonstationary signals. The proper technique is crucial, especially because instrumental problems were detected in early 2001, and a warning was released that EPTOMS data past mid 2000 should not be used for trend analysis (http://toms.gsfc.nasa.gov/news/news.html).

In the next Section we give details on the data and methods. Special care is taken to remove the quasi-biennial oscillations (QBO) from the signals, because such background cycles are known to distort correlation exponents (Jánosi and Müller, 2005). Then we present a detailed map of exponent values and comparison with existing results for other meteorological variables. We argue that the correlation properties of the total ozone time series suggest the dominance of dynamical processes, thus TO outside the polar regions over a given geographic location can be considered as a "passive" scalar, similarly to temperature.

\section{Data and methods}

The TOMS instruments measure backscattered ultraviolet radiation at six wavelengths, and provide a contiguous gridded mapping of TO with a spatial resolution of $1.0^{\circ} \times 1.25^{\circ}$ (lat/long). In order to minimise the effects of known instrumental distortions at high solar zenith angles and missing

Published by Copernicus Publications on behalf of the European Geosciences Union and the American Geophysical Union. 


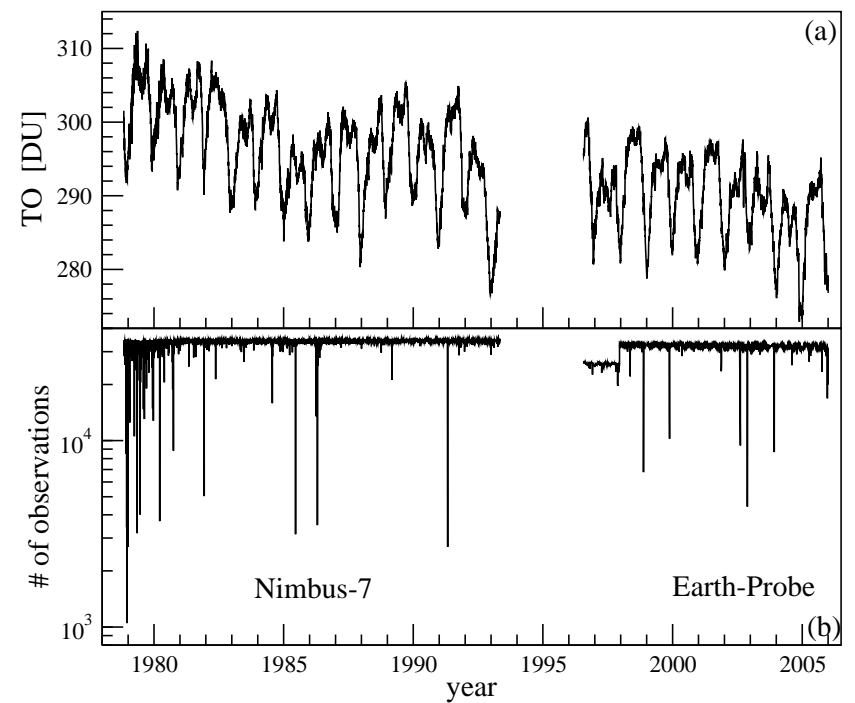

Fig. 1. (a) Daily mean total ozone (in Dobson units) averaged in the band $60^{\circ} \mathrm{S}$ and $60^{\circ} \mathrm{N}$ latitude for the TOMS data bank. (b) Number of daily observations for the Nimbus-7 and Earth-Probe satellites (note the logarithmic vertical scale).

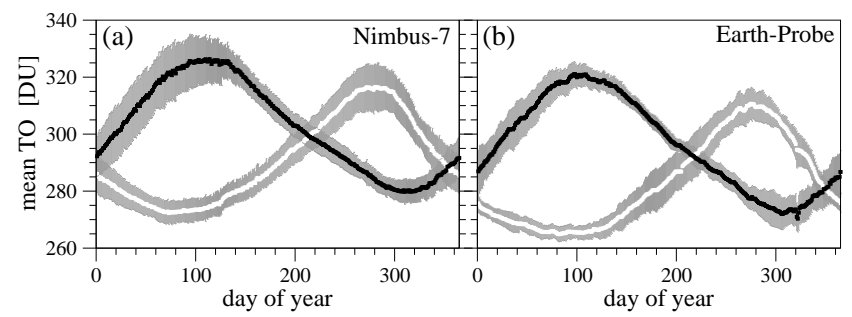

Fig. 2. Annual cycle of daily mean total ozone (TO) averaged over $0^{\circ}-60^{\circ} \mathrm{N}$ lat (northern hemisphere, black symbols) and $0^{\circ}-60^{\circ} \mathrm{S}$ lat (southern hemisphere, white symbols) for (a) N7-TO, and (b) EP-TO. Gray bands indicate one sigma standard deviations.

polar night intervals, data evaluation is restricted between latitudes $60^{\circ} \mathrm{S}$ and $60^{\circ} \mathrm{N}$ covering $\sim 87 \%$ of the earth surface. Daily average TO values over this band are plotted in Fig. 1a, the number of observations is shown in Fig. $1 \mathrm{~b}$.

Figure 2 illustrates the daily mean TO levels averaged separately over the northern and southern hemispheres, for a given calendar day. The total column ozone has very similar annual cycles for both satellite records (apart from the clear baseline drop of EP data), the different amplitudes and phase shift between the hemispheres explain the net annual periodicity visible in Fig. 1a.

Since a reasonable application of DFA requires the removal of all dominant periodicities, we have performed a detailed spectral analysis of TO time series for each geographic location. We have implemented the Lomb periodogram algorithm (Press et al., 1992) in order to properly treat missing

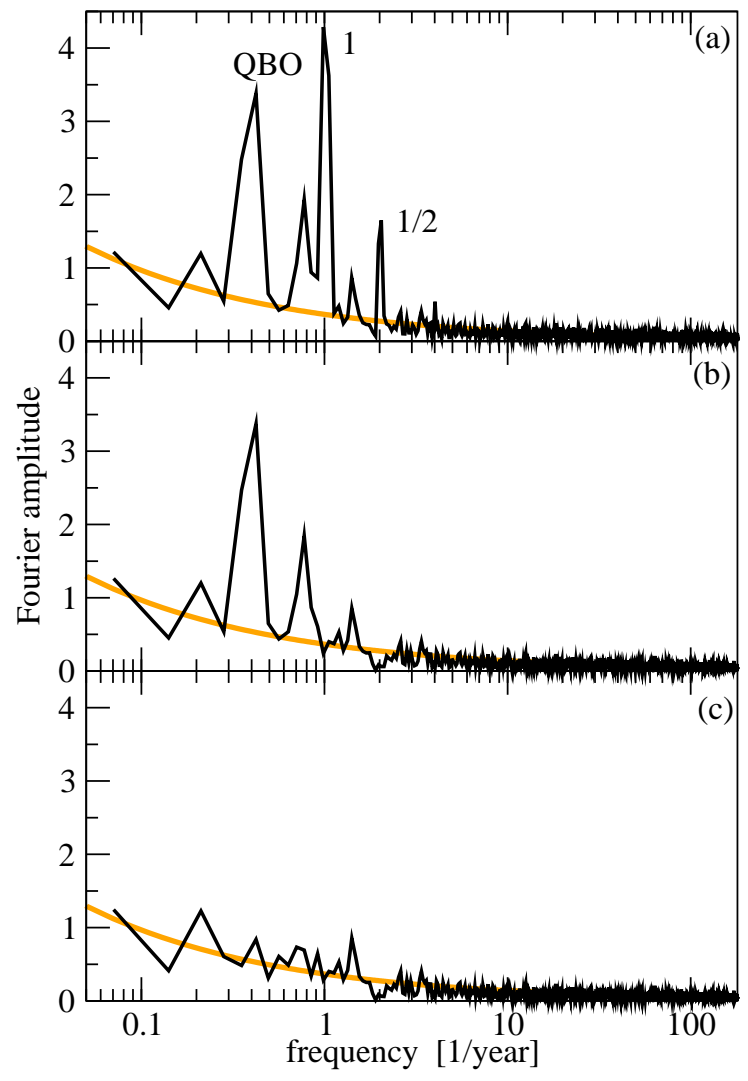

Fig. 3. Unnormalised power spectrum as a function of frequency (note the logarithmic scale) for the geographic location $0.5^{\circ} \mathrm{N}$, $0.625^{\circ}$ E. (a) $\mathrm{N} 7$ signal. (Leading period lengths are labelled.) (b) N7 signal after removing the annual periodicities. (c) N7 signal after Wiener filtering for QBO. Orange lines indicate a power-law background with an exponent $-1 / 2$.

data points. The spectra for a given geographic location are very similar for both instruments. Since the EP records are shorter, somewhat higher noise level and peak broadening are experienced. Nevertheless the main features are retained for both satellite measurements: the dominant periodicities are semi-annual, annual, and quasi-biennial (Fig. 3a). The TO levels are known to be affected also by the solar cycle of $\sim 11$ years (Hood, 1997; Calisesi and Matthes, 2006), however the TOMS records are too short and the amplitude of the solar signal is too low for a direct detection by Fourier methods.

As a first step of filtering, the annual periodicity is removed from the daily values $\mathrm{TO}_{i}$ by the long-time climatological mean $\langle\mathrm{TO}\rangle_{d}$ for the given calendar day $d=1 \ldots 365$ (leap days are omitted) to get the ozone-anomaly series $\mathrm{TOa}_{i}=\mathrm{TO}_{i}-\langle\mathrm{TO}\rangle_{d}$. This procedure cannot remove smeared oscillations from the records, such as QBO (Fig. 3b) or a gradual shift of the annual means. In order to remove the QBO background as well, the Wiener filter method (Press et 


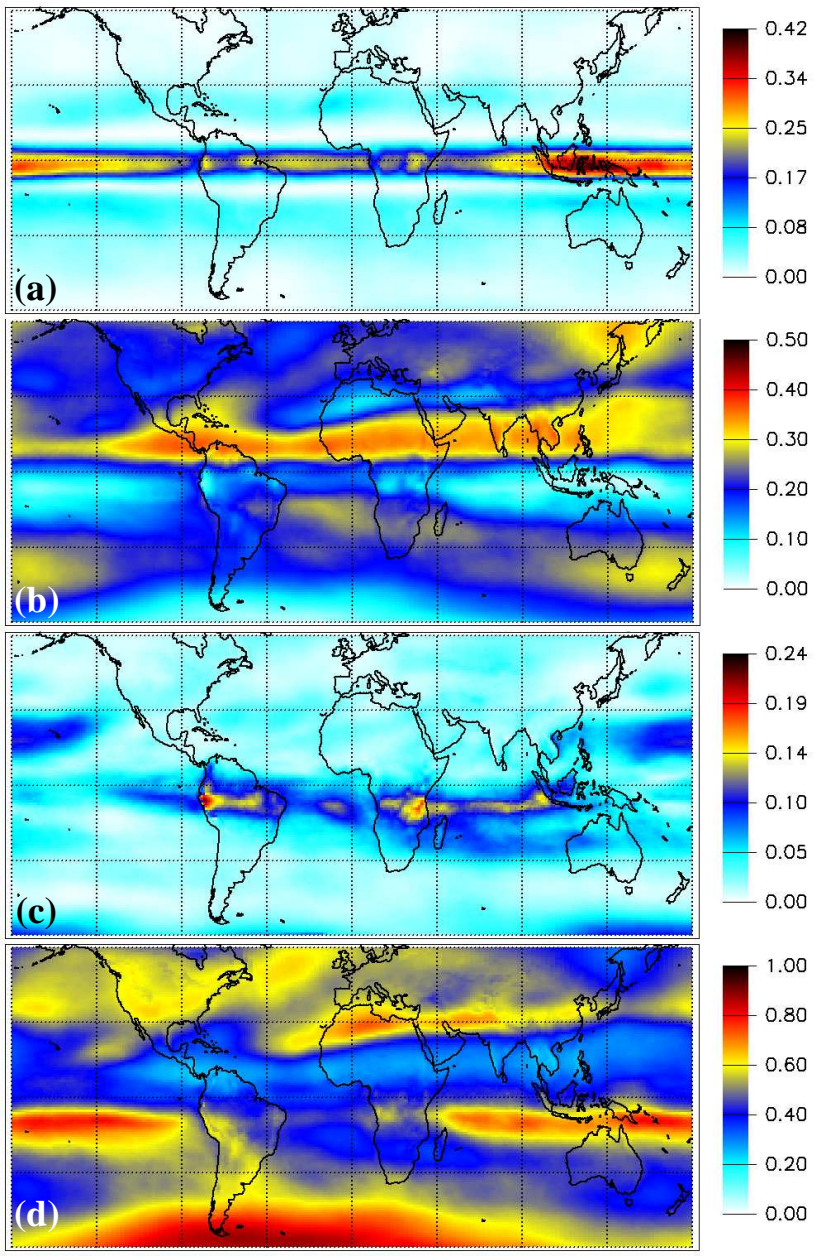

Fig. 4. Geographic distribution of the N7 spectral peak intensities indicated in Fig. 3: (a) QBO peak(s) between 2 and 3 years; (b) Annual peak ( $1 \pm 0.1$ year); (c) semi-annual peak $(0.5 \pm 0.05$ year); (d) the continuum background (total area minus the area under the three peaks). Each individual power spectrum is normalised, note the different colour scales.

al., 1992; Hegger et al., 1999) is used by cutting the spectral amplitudes to base-line values in the interval of periods 1.14.3 years. The result for an equatorial location is shown in Fig. 3c.

The relative peak heights at the different characteristic frequencies (Fig. 3a) depend on the geographic location. The spectral intensity of the semi-annual, annual, and QBO components is estimated by integrating the area under the peaks of normalised spectra. The map in Fig. 4a illustrates that QBO is almost negligible away from the equator by $\sim 10^{\circ}$ latitude. Fig. $4 \mathrm{~b}$ reveals a marked asymmetry between the hemispheres regarding the strength of annual periodicity, which is also clear in Fig. 2. Similar north-south asymmetry is reflected in the semi-annual periodicities (Fig. 4c). It is quite remarkable that large areas exhibit very weak peri- odicities (Fig. 4d), especially over the South Atlantic Basin. Note that maps for Earth-Probe data show very similar features with negligible differences, therefore we use only the (longer) Nimbus-7 record for visualisation.

As a next step, the Wiener filtered ozone-anomaly series are evaluated by DFA procedure. The method is described in hundreds of papers (http://www.physionet.org/physiotools/ dfa/citations.shtml), therefore here we settle for a very short summary. The integrated anomaly time series (so called profile) is divided into nonoverlapping segments of equal length $n$. In each segment, the local trend is fitted by a polynomial of order $p$ and the profile is detrended by subtracting this local fit. The strength of fluctuations is measured by the standard deviation in the detrended segment averaged over all the segments $\left\langle F_{p}(n)\right\rangle$. A power-law relationship between $\left\langle F_{p}(n)\right\rangle$ and $n$ indicates scaling with an exponent $\delta$ (DFA$p$ exponent): $\left\langle F_{p}(n)\right\rangle \sim n^{\delta}$. Notice that such a process has a power-law autocorrelation function $A(\tau)$ and a power spectrum $S(f)$

$A(\tau) \sim \tau^{-\alpha}, \quad S(f) \sim f^{-\beta}$,

where stationarity requires $0<\alpha<1$ and $0<\beta<1, \tau$ is the usual time lag and $f$ is the frequency variable of the Fourier transform. The relationships between the correlation exponents are (Koscielny-Bunde et al., 1998; Talkner and Weber, 2000)

$\alpha=2(1-\delta), \quad \beta=2 \delta-1$.

Processes of long-range temporal correlations and finite variance are characterised by DFA exponents $1>\delta>1 / 2$, uncorrelated time series (e.g., pure random walk) obey $\delta=1 / 2$. Signals with $\delta<1 / 2$ are called antipersistent, expressing the behaviour that an increasing trend in the past implies a decreasing trend in the future, and vice versa.

Local polynomial fits of order $p$ eliminate polynomial background trends of order $p-1$, thus DFA-1 does not remove any incidental nonstationarity, DFA-2 can discard slow linear trends, etc. Long-range correlation is inferred for a given time series when the exponent $\delta$ does not depend on $p$.

After checking that both N7 and EP filtered ozoneanomalies obey long-range dependence, an important result by Chen et al. (2002) can be exploited in order to improve the statistics. Namely, if a record has positive long-range correlations $(\delta>1 / 2)$, segments up to $50 \%$ of the total length can be removed. DFA tests on the rest stitched together show the same scaling behaviour as the whole record. Based on this finding, we merged the N7 and EP filtered anomaly series for a given location resulting in record lengths around 23 years. An example for DFA scaling is shown in Fig. 5.

An essential practical limitation of the DFA method is that the maximal segment size can not be longer than roughly one quarter of the total length. This has the consequence that scaling can be rigorously established only up to timescales for a few years for TO data. Still, the DFA curves similar to 


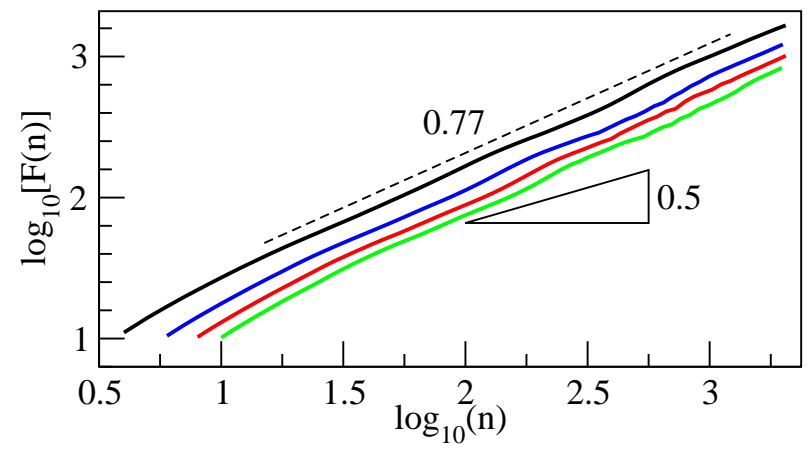

Fig. 5. DFA curves for the filtered and merged data (see text) with linear (black), parabolic (blue), cubic (red), and fourth order polynomial (green) local detrending. Characteristic slopes are indicated. $\left(51.5^{\circ} \mathrm{N}, 110.625^{\circ} \mathrm{E}\right)$.

Fig. 5 do not show a systematic breakdown at a well defined threshold time, apart from steeply increasing irregular fluctuations for too large $n$ values. Therefore we use the term "long-range correlation" to indicate the scaling behaviour of DFA curves over the intervals permitted by the record lengths of the time series, and we do not mean that the fluctuations have an infinite memory.

In a recent paper, Vyushin et al. (2007) determined the global correlation properties of TO signals from the same TOMS (version 8) data base. Since their results are quite different from ours (see below), here we summarise the most essential steps of their procedure. Instead of daily data, they evaluated time series of zonal and gridded $\left(10^{\circ}\right.$ latitude by $30^{\circ}$ longitude grid) monthly mean total ozone values. Ground based TO measurements were used to fill the gap (see Fig. 1) to obtain nearly continuous time series of 324 monthly mean values. The deterministic part was separated by multilinear regression of 20 coefficients in a spectral decomposition model representing the long term average, seasonal cycle, QBO, solar flux, and a long term trend. The long term trend was described by two different methods, a piecewise-linear trend and the equivalent effective stratospheric chlorine (EESC) time series. EESC is a measure designed to quantify the combined effect of halogens (chlorine and bromine) on ozone depletion in the stratosphere (e.g., Newman et al., 2007; WMO, 2007).Hurst exponents were estimated by computing the power spectra for the residuals, and fitting a power-law for the low frequency part between 1 and 27 years with either a maximum likelihood method or a log-linear regression of the periodogram. Note that the Hurst exponent is mathematically equivalent with the DFA exponent $\delta$ for an infinite time series, however they can numerically differ for a finite data set (Pilgram and Kaplan, 1998).

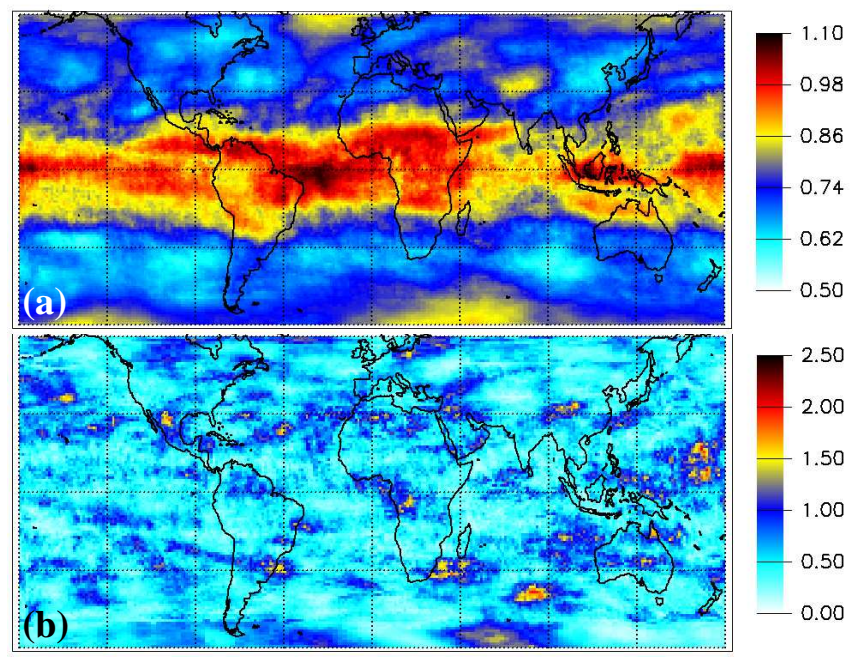

Fig. 6. (a) Fitted DFA-3 (cubic local detrending) exponent values for the ozone anomaly records for each grid point. (b) Residual percentage variance $100\left(1-r^{2}\right)$ for the linear regression of DFA-3 curve (see Fig. 5) at each grid point.

\section{Results}

We preformed a DFA analysis for the filtered and merged $\mathrm{N} 7-\mathrm{EP}$ records for each grid point between $65^{\circ} \mathrm{S}$ and $65^{\circ} \mathrm{N}$ latitudes in the TOMS data base. (This band is little wider than the maps shown, in order to compare the results with temperature data, see below.) Since we could not check visually all the 37440 individual curves for occurrent residual anomalies, we extracted the DFA-3 slopes of cubic local detrending which eliminates any contingent linear or quadratic tendency from the data. The results are shown in Fig. 6a. The quality of exponents is visualised in Fig. 6b by computing the regression coefficient $r$ for the linear fits on the double-logarithmic DFA-3 curves (c.f., Fig. 5), and plotting the residual percentage variance $100\left(1-r^{2}\right)$ by colour coding. The unstructured patchy map suggests that the dominant source of errors is statistical fluctuations as a consequence of restricted record lengths, indeed.

The main feature of the geographic distribution of exponent values (Fig. 6a) is the marked belt of strong correlations between $\sim 20^{\circ} \mathrm{S}$ and $20^{\circ} \mathrm{N}$ latitudes. 866 grid points $(\sim 2.5 \%)$ have fitted exponent values slightly larger than 1 (the absolute maximum is $1.09 \pm 0.04$ ), which indicates that our filtering method is not perfect (we have no reason to assume that TO fluctuations obey infinite variance). The absolute minimum value is $0.57 \pm 0.03$, therefore each record exhibits long-range correlations.

The strength of correlations has negligible seasonality. This we checked by the method of "cutting and stitching" (Chen et al., 2002) separately for the summer and winter halfyears (1 June-30 November, and 1 December-31 May). The 
maps similar to Fig. 6a do not show systematic differences, the overall pattern is the same in both half-years.

Atmospheric variables commonly exhibit long-range asymptotic correlations. Besides the detailed investigation of terrestrial and sea surface temperature records (Pelletier, 1997; Koscielny-Bunde et al., 1998; Talkner and Weber, 2000; Kantelhardt et al., 2001; Weber and Talkner, 2001; Király and Jánosi, 2002; Blender and Fraedrich, 2003; Eichner et al., 2003; Fraedrich, 2003; Fraedrich and Blender, 2003; Fraedrich et al., 2003; Monetti et al., 2003; PattantyúsÁbrahám et al., 2004; Király and Jánosi, 2005; Bartos and Jánosi, 2006; Huybers and Curry, 2006; Király et al., 2006; Rybski et al., 2006), power-law autocorrelation detected for pressure height fluctuations (Tsonis et al., 1999), total ozone level (Toumi et al., 2001; Jánosi and Müller, 2005; Vyushin et al., 2007) or carbon-dioxide (Patra et al., 2006), only to mention a few. Since we have data for daily mean temperature correlations, we can directly compare them with the present results for TO. The maps of exponent distributions for temperature show much more complicated patterns (Bartos and Jánosi, 2006; Király et al., 2006), therefore we determined the zonal averages for both sets of exponents. The result is shown in Fig. 7a.

The agreement of zonally averaged correlation exponents for daily surface temperature and TO is quite striking. One might expect much higher variablity for temperature data, since local factors (topography, land coverage, vertical convection, etc.) obviously affect strongly how the temperature fluctuates at $2 \mathrm{~m}$ height. The variation of TO levels, in contrast, reflects changes mostly in the lower stratosphere, where ozone concentration is the highest. And indeed, the variability of the correlation exponents with longitude is much stronger for temperature (Bartos and Jánosi, 2006; Király et al., 2006) than for TO (Fig. 6a). However, the impact of local factors on the correlation exponents of temperature is obviously not strong enough to show up in the zonal average.

Finally, we show a comparison with the results of Vyushin et al. (2007) in Fig. 7b. They determined Hurst exponents for zonally averaged monthly mean ozone levels for the same interval (January 1979 - December 2005) and for the same geographic area $\left(60^{\circ} \mathrm{S}-60^{\circ} \mathrm{N}\right)$. We plotted their Hurst exponents computed by the widely used log-linear regression and based on the EESC estimate for the long term trend. Hurst exponents computed employing a maximum likelihood method in contrast to a log-linear regression show somewhat less latitudinal variation Vyushin et al. (2007). Further, when a piecewise-linear trend is used to describe the long term trend, Hurst exponents for the Northern Hemisphere decrease by about 0.1 , leading to values not significantly different from 0.5 and thus to a loss of long range correlation in the Northern Hemisphere midlatitudes. Note again that the Hurst exponent should essentially be the same as the DFA exponent $\delta$. However, all of the zonally averaged Hurst exponents reported by Vyushin et al. (2007) show a stronger latitudinal variation than our results for $\delta$ (see Fig. 7b). Similarly, the

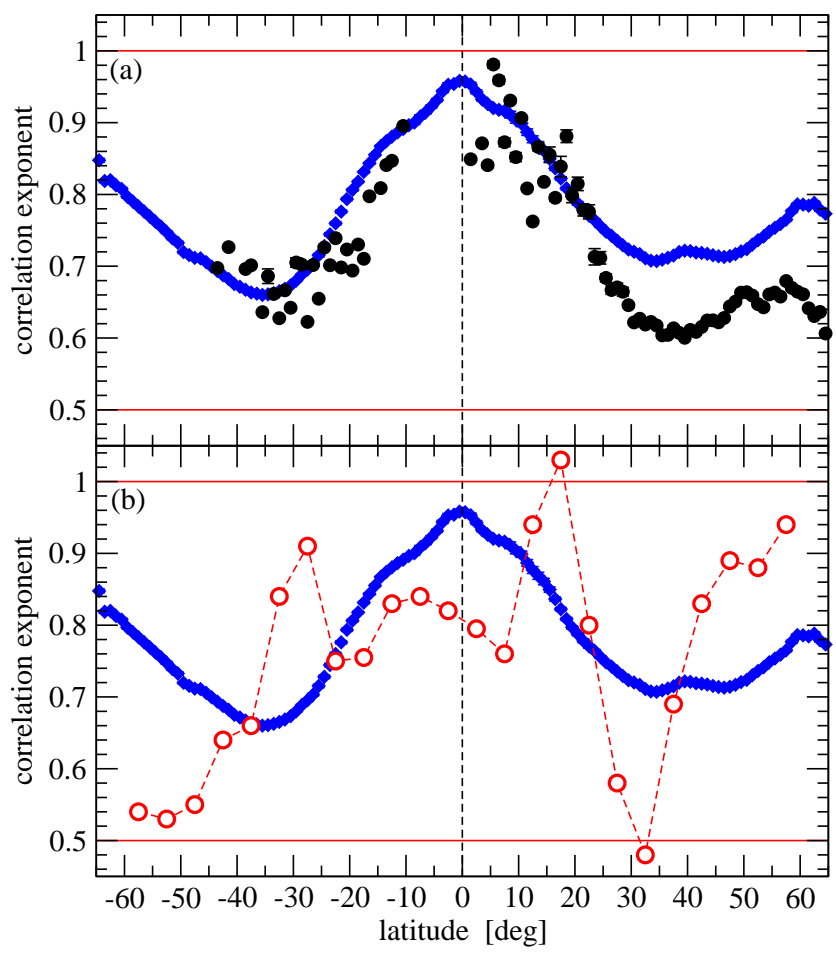

Fig. 7. Comparison of zonally averaged DFA exponent values. (a) Black symbols: daily mean temperature anomalies for terrestrial stations (Király et al., 2006). Blue symbols: data from Fig. 6a. The error bars are comparable with the symbol sizes. (b) The blue curve is the same as in (a). Red symbols: Hurst exponents for monthly mean TO levels by Vyushin et al. (2007) computed using log-linear regression based on the EESC estimate for the long term trend (their Fig. 4b).

geographic distribution (Fig. 12 bottom panel in Vyushin et al., 2007) is different from our map Fig. 6a, they obtained a strong longitudinal variability. The discrepancy can not be related to the fact that we evaluated daily data instead of spatial and monthly mean values. When we computed average values over the same grid $\left(10^{\circ} \times 30^{\circ}\right.$ lat/long $)$ and time interval (1 month), and performed our filtering procedure to remove annual and QBO cycles, the residuals exhibited the same correlation properties with exponent values significantly larger than $1 / 2$ everywhere.

\section{Discussion}

The main difference between our results and the Hurst exponents computed by Vyushin et al. (2007) shown in Fig. 7b is that we do not see decaying correlations toward the Antarctic, in the contrary, the exponent values start to increase at latitudes poleward of $\sim 40^{\circ}$. One key step in correlation analysis is the proper separation of deterministic periodicities and long term trends from the residual fluctuations. The 


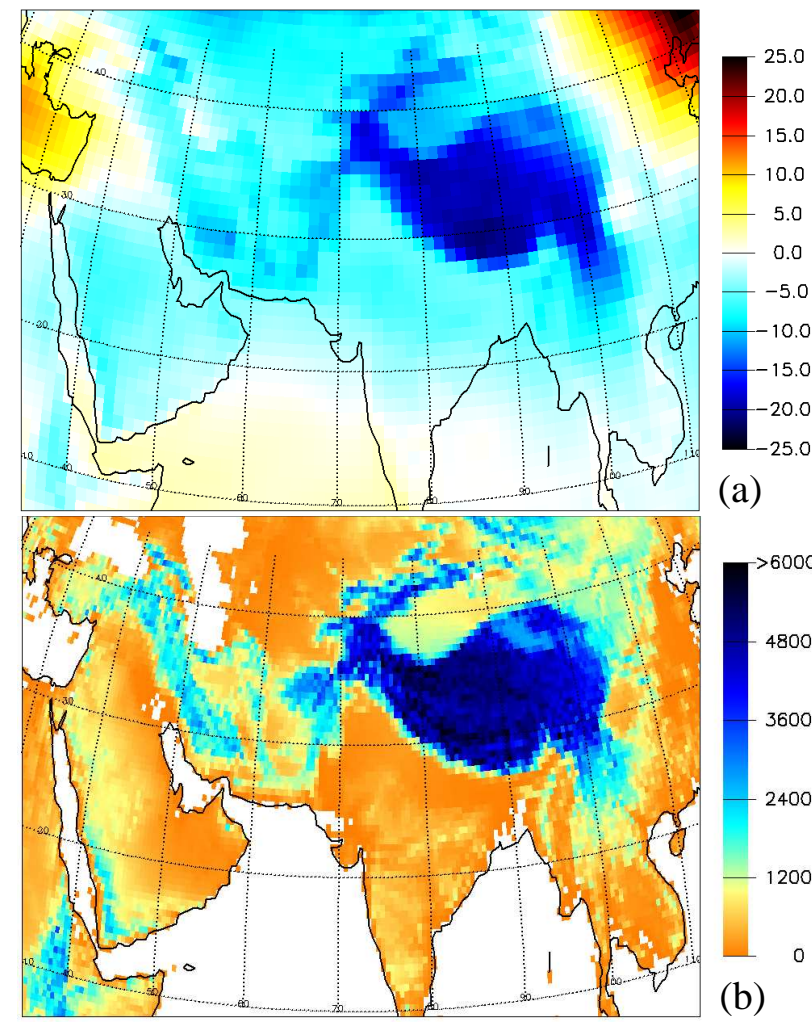

Fig. 8. (a) The difference between the average TO level (over the whole record) for a given grid point and the zonal average for the given latitude (in Dobson units). (b) Topographic map for the same region as in (a). Black colour indicates all the sites of elevation larger than $6000 \mathrm{~m}$.

complicated spectral decomposition procedure by Vyushin et al. (2007) mentioned at the end of Sect. 2 might contain some uncertainties. For example, if the background trend is estimated by a picewise-linear trend, the choice of the breaking point is somewhat arbitrary. Likewise, if the background trend is described by the EESC time series, there is no unique definition of EESC (Newman et al., 2007). Moreover, the calculated Hurst exponents are rather sensitively dependent on the frequency interval used for the parameter estimation.

Already the maps of spectral intensities in Fig. 4 indicate that TO variations are strongly affected by the atmospheric circulation. Of course, the obligate connection was recognised much earlier (see e.g., Dobson, 1968; Schoeberl, 1987; Salby and Callaghan, 1993). Clearly, the values of correlation exponents of TO are dominated by dynamical processes. Nonetheless, the fact that ozone abundances in recent years over the extrapolar regions of the Northern and Southern Hemisphere are $3 \%$ and $6 \%$ below pre-1980 values, respectively, is due to anthropogenic ozone depleting substances, that is due to chemistry (WMO, 2007). But this chemical effect is apparently not strong enough to impact correlation exponents.

A particularly transparent linkage between the TO level and airflow dynamics is represented by the ozone "miniholes", which are spatially localised and transient ozone depletion events (McKenna et al., 1989; Peters et al., 1995).

Typical for the dynamics of mini-holes is a lifting of the tropopause above a tropospheric anticyclone and poleward motion of ozone poor subtropical air in the upper troposphere and lower stratosphere, which, in combination, causes a reduction in column TO (Peters et al., 1995; Reid et al., 2000). The dynamics of mini-holes further results in equatorward excursions of polar air in the mid-stratosphere; in a situation when this air is chemically depleted by halogen chemistry in the polar vortex, particularly low ozone mini-holes may occur (Weber et al., 2002; Keil et al., 2007)

The mini-hole mechanism is demonstrated nicely by the visualisation of a "permanent" mini-hole over the Himalaya Mountains in Fig. 8a, where the difference between the average total column ozone (computed over the whole period for a given gridpoint) and the zonal average determined along each degree latitude is plotted in a colour scale. (The topographic setting for the same area is shown in in Fig. 8b.)

The strong coupling between measured TO and circulation patterns is evident (Fusco and Salby, 1999), however the general view assumes a restricted temporal range for correlations. The results in Fig. 7a suggest that the source of longrange correlations is in the dynamics of atmospheric circulation for both TO and temperature. It is well known that highfrequency atmospheric processes are crucial in achieving the long-term balance of energy, momentum, and water vapour in the atmosphere (Tsonis et al., 1999). Long-range temporal correlations in the fluctuations mean that an anomaly of a given sign persists much longer (in statistical sense) than the characteristic timescales of the physical processes determining the variability of the meteorological parameter. This behaviour is expected when the atmospheric flow is strongly coupled to the slowly varying components of the climate system such as the oceanic gyre modes. For example, a slowly changing sea surface temperature forcing can affect atmospheric flow for decades (Latif and Barnett, 1996).

Ozone and temperature share a number of common features. For example, the main source of "production" is around the equator, but both ozone and temperature are "generated" over large extratropical areas with decreasing intensities. Both ozone and heat are transported toward the poles by the atmospheric flow, mostly cyclones in the troposphere and by the Brewer-Dobson circulation in the stratosphere (Plumb and Eluszkiewicz, 1999). The curves in Fig. 7a are very similar, the smooth meridional changes of average correlation exponents are rather impressive. This observation fits to our present understanding of atmospheric dynamics, namely that the tropospheric and stratospheric processes are more strongly coupled than was believed earlier (Haynes, 2005). 
Acknowledgements. This work was partly supported by the Hungarian Science Foundation (OTKA) under Grant No. T047233. IMJ thanks for a János Bolyai Research Scholarship of the Hungarian Academy of Sciences.

Edited by: A. Tsonis

Reviewed by: one anonymous referee

\section{References}

Bartos, I. and Jánosi, I. M.: Nonlinear correlations of daily temperature records over land, Nonlin. Processes Geophys., 13, 571-576, 2006, http://www.nonlin-processes-geophys.net/13/571/2006/.

Blender, R. and Fraedrich, K.: Long time memory in global warming simulations, Geophys. Res. Lett., 30, 1769, doi:10.1029/2003GL017666, 2003.

Calisesi, Y. and Matthes, K., The middle atmospheric ozone response to the 11-year solar cycle, Space Sci. Rev., 125, 273-286, 2006.

Chen, Z., Ivanov, P. C., Hu, K., and Stanley, H. E., Effect of nonstationarities on detrended fluctuation analysis, Phys. Rev. E, 65, 041107, 2002.

Dobson, G. M. B.: Forty years' research on atmospheric ozone at Oxford: a history, Appl. Opt., 7(3), 387-405, 1968.

Eichner, J. F., Koscielny-Bunde, E., Bunde, A., Havlin, S., and Schellnhuber, H.-J.: Power-law persistence and trends in the atmosphere: A detailed study of long temperature records, Phys. Rev. E, 68, 046133, 2003.

Eyring, V., Butchart, N., Waugh, D. W., Akiyoshi, H., Austin, J., Bekki, S., Bodeker, G. E., Boville, B. A., Brühl, C., Chipperfield, M. P., Cordero, E., Dameris, M., Deushi, M., Fioletov, V. E., Frith, S. M., Garcia, R. R., Gettelman, A., Giorgetta, M. A., Grewe, V., Jourdain, L., Kinnison, D. E., Mancini, E., Manzini, E., Marchand, M., Marsh, D. R., Nagashima, T., Nielsen, E., Newman, P. A., Pawson, S., Pitari, G., Plummer, D. A., Rozanov, E., Schraner, M., Shepherd, T. G., Shibata, K., Stolarski, R. S., Struthers, H., Tian, W., and Yoshiki, M.: Assessment of temperature, trace species and ozone in chemistry-climate simulations of the recent past, J. Geophys. Res., 111(D22), D22308, doi: 10.1029/2006JD007327, 2006.

Fusco, A. C. and Salby, M. L.: Interannual variations of total ozone and their relationship to variations of planetary wave activity, J. Climate, 12, 1619-1629, 1999.

Fraedrich, K.: Predictability: short- and long-term memory of the atmosphere, in: Chaos in Geophysical Flows, edited by: Boffetta, G., Larcotta, S., Visconti, G., and Vulpiani, A., Otto Editore, Torino, 63-104, 2003.

Fraedrich, K. and Blender, R.: Scaling of atmosphere and ocean temperature correlations in observations and climate models, Phys. Rev. Lett., 90, 108501, 2003.

Fraedrich, K., Luksch, U., and Blender, R. A.: 1/f-model for long time memory of the ocean surface temperature, Phys. Rev. E, 70, 037301, 2003.

Govindan, R. B., Bunde, A., and Havlin, S.: Volatility in atmospheric temperature variability, Physica A, 318, 529-536, 2003.

Haynes, P. H.: Stratospheric dynamics, Ann. Rev. Fluid Mech., 37, 263-293, 2005.
Hegger, R., Kantz, H., and Schreiber, T.: Practical implementation of nonlinear time series methods: The TISEAN package, Chaos, The software package is publicly available at http: //www.mpipks-dresden.mpg.de/ tisean, 9, 413-435, 1999.

Hood, L. L.: The solar cycle variation of total ozone: Dynamical forcing in the lower stratosphere, J. Geophys. Res. D, 102, 1355$1370,1997$.

Huybers, P. and Curry, W.: Links between the annual, Milankovitch, and continuum of temperature variability, Nature, 441, 329-332, 2006.

Jánosi, I. M. and Müller, R., Empirical mode decomposition and correlation properties of long daily ozone records, Phys. Rev. E, 71, 056126, 2005.

Kantelhardt, J. W., Koscielny-Bunde, E., Rego, H. H. A., Havlin, S., and Bunde, A.: Detecting long-range correlations with detrended fluctuation analysis, Physica A, 295, 441-454, 2001.

Keil, M., Jackson, D. R., and Hort, M. C.: The January 2006 low ozone event over the UK, Atmos. Chem. Phys., 7, 961-972, 2007.

Király, A., Bartos, I., and Jánosi, I.M.: Correlation properties of daily temperature anomalies over land, Tellus A, 58, 593-600, 2006.

Király, A., and Jánosi, I.M.: Stochastic modeling of daily temperature fluctuations, Phys. Rev. E, 65, 0511021, 2002.

Király, A. and Jánosi, I.M.: Detrended fluctuation analysis of daily temperature records: Geographic dependence over Australia, Met. Atmos. Phys., 88, 119-128, 2005.

Koscielny-Bunde, E., Bunde, A., Havlin, S., Roman, H. E., Goldreich, Y., and Schellnhuber, H. J.: Indication of a universal persistence law governing atmospheric variability, Phys. Rev. Lett., 81, 729-732, 1998.

Latif, M. and Barnett, T. P.: Decadal climate variability over the North Pacific and North America: Dynamics and predictability, J. Climate, 9, 2407-2423, 1996.

McKenna, D. S., Jones, R. L., Austin, J., Browell, E. V., McCormick, M. P., Krueger, A. J., and Tuck, A. F.: Diagnostic Studies of the Antarctic Vortex During the 1987 Airborne Antarctic Ozone Experiment: Ozone Miniholes, J. Geophys. Res., 94, $11641-11668,1989$.

Monetti, R. A., Havlin, S., and Bunde, A.: Long term persistence in the sea surface temperature fluctuations, Physica A, 320, 581589, 2003.

Newman, P. A., Daniel, J. S., Waugh, D. W., and Nash, E. R.: A new formulation of equivalent effective stratospheric chlorine (EESC), Atmos. Chem. Phys. Discuss., 7, 3963-4000, 2007, http://www.atmos-chem-phys-discuss.net/7/3963/2007/.

Patra, P. K., Santhanam, M. S., Manimaran, P., Takigawa, M., and Nakazawa, T.: 1/f noise and multifractality in atmospheric-CO2 records, arXiv:nlin/0610038v1, 2006.

Pattantyús-Ábrahám, M., Király, A., and Jánosi, I. M.: Nonuniversal atmospheric persistence: different scaling of daily minimum and maximum temperatures, Phys. Rev. E, 69, 021110, 2004.

Pelletier, J. D.: Analysis and modeling of the natural variability of climate, J. Climate, 10, 1331-1342, 1997.

Peng, C. K., Buldyrev, S. V., Havlin, S., Simons, M., Stanley, H. E., and Goldberger, A. L.: Mosaic organization of DNA nucleotides, Phys. Rev. E, 49, 1685-1689, 1994.

Peng, C. K., Havlin, S., Stanley, H. E., and Goldberger, A. L.: Quantification of scaling exponents and crossover phenomena in 
nonstationary heartbeat time series, Chaos, 5, 82-87, 1995.

Peters, D., Egger, J., and Entzian, G.: Dynamical aspects of ozone mini-hole formation. Met. Atmos. Phys., 55, 205-214, 1995.

Pilgram, B. and Kaplan, D. T.: A comparison of estimators for $1 / \mathrm{f}$ noise, Physica D, 114, 108-122, 1998.

Plumb, R. A. and Eluszkiewicz, J.: The Brewer-Dobson circulation: dynamics of the tropical upwelling, J. Atmos. Sci., 56, 868-890, 1999.

Press, W. H., Teukolsky, S. A., Vetterling, W. T., and Flannery, B. P.: Numerical Recipes in C, Cambridge University Press, Cambridge, 1992.

Reid, S., Tuck, A., and Kiladis, G.: On the changing abundance of ozone minima at northern midlatitudes, J. Geophys. Res., 105(D10), 12 169-12 180, 2000.

Rybski, D., Bunde, A., Havlin, S., and von Storch, H.: Long-term persistence in climate and the detection problem, Geophys. Res. Lett., 33, L06718, doi:10.1029/2005GL025591, 2006.

Salby, M. L. and Callaghan, P. F.: Fluctuations of total ozone and their relationship to stratospheric air motions, J. Geophys. Res., 98, 2715-2727, 1993.

Schoeberl, M. R.: Dynamics of the middle atmosphere, Rev. Geophys., 25, 501-507, 1987.

Talkner, P. and Weber, R. O.: Power spectrum and detrended fluctuation analysis: Application to daily temperatures, Phys. Rev. E, 62, 150-160, 2000.
Toumi, R., Syroka, J., Barnes, C., and Lewis, P.: Robust nonGaussian statistics and long-range correlation of total ozone, Atmos. Sci. Lett., 2, 94-103, 2001.

Tsonis, A. A., Roebber, P. J., and Elsner, J. B.: Long-range correlations in the extratropical atmospheric circulation: Origin and implications, J. Climate, 12, 1534-1541, 1999.

von Storch, H. and Zwiers, F.: Statistical Analysis in Climate Research, Cambridge University Press, Cambridge, 1999.

Vyushin, D. I., Fioletov, V. E., and Shepherd, T. G.: Impact of long-range correlations on trend detection in total ozone, J. Geophys. Res., 112, D14307, doi:10.1029/2006JD008186, 2007.

Weatherhead, E. C. and Andersen, S. B.: The search for signs of recovery of the ozone layer, Nature, 441, 39-45, 2006.

Weber, R. O. and Talkner, P.: Spectra and correlations of climate data from days to decades, J. Geophys. Res. D, 106, $20131-$ $20144,2001$.

Weber, M., Eichmann, K.-U., Bramstedt, K., Hild, L., Richter, A., Burrows, J. P., and Müller, R.: The cold Arctic winter 1995/96 as observed by GOME and HALOE: Tropospheric wave activity and chemical ozone loss, Q. J. R. Meteorol. Soc., 128, 12931319, 2002.

WMO: Scientific assessment of ozone depletion: 2006, Global Ozone Research and Monitoring Project-Report No. 50, Geneva, Switzerland, 2007. 